\title{
Effect of 12 Months of Exercise With Stachys Lavandulifolia Consumption on Anxiety, Metabolic Syndrome Profiles and Antioxidant Defense and Lipid Peroxidation in Women With Metabolic Syndrome
}

Ali Osali ( $\square$ osalialiphd@gmail.com )

University of Bonab

Alireza Rostami

University of Bonab

Research

Keywords: Exercise, Anxiety, Antioxidant Defense, Lipid Peroxidation, Stachys lavandulifolia, and Metabolic syndrome

Posted Date: July 6th, 2021

DOI: https://doi.org/10.21203/rs.3.rs-643956/v1

License: (1) This work is licensed under a Creative Commons Attribution 4.0 International License. Read Full License 


\section{Abstract}

Background: The purpose of this study was to investigate the effect of 12 months of aerobic exercise combining stachys lavandulifolia (S. lavandulifolia) consumption on anxiety, Metabolic Syndrome profiles and antioxidant defense (Glutathione) and lipid peroxidation (Malondialdehyde) in 50-65 years old women with metabolic syndrome.

Methods: 48 women with Metabolic syndrome were randomly divided into four groups: exercise $(n=12)$, exercise+S. lavandulifolia $(n=12)$, S. lavandulifolia $(n=12)$ and control group $(n=12)$. S. lavandulifolia groups consumed $3 \mathrm{~g}$ aerial parts of $\mathrm{S}$. lavandulifolia daily. Training groups performed an exercise protocol of aerobic exercise for 12 months (three sessions per week). Blood samples were obtained before and after training period for antioxidant indicators and lipid degradation measurement. Also, Beck anxiety questionnaire used for evaluating levels of anxiety. T-test and one-way analysis of variance were used for the evaluation of within-group and between-group differences, respectively.

Results: A significant increase was observed in serum levels of Malondialdehyde ( $P=0.004)$, Catalase indexes (Pvalue $=0.01$ ), and Glutathione $(P=0.001)$ in the training group and $S$. lavandulifolia groups after 12 months. Body weight, BMI, and SBP and Anexiety was decreased significantly greater in exercise $+\mathrm{S}$. lavandulifolia group compared to control, exercise and $S$. lavandulifolia groups $(P=0.001)$

Conclusion: Anxiolytic effect and Anti-Oxidative Stress Activity was seen, so taking S. lavandulifolia along with exercises may have beneficial effects on reinforcement the antioxidant system and prevention of anxiety and The negative effects of indicators related to cardiovascular disease in women with metabolic syndrome.

\section{Background}

Ageing is the process during which structural and functional changes accumulate in an organism as a result of the passage of time. Aging is an inevitable reality and increasing the elderly population around the world is a matter of attention and it is very important that the World Health Organization has estimated the total number of seniors in 2006 for about 700 millions in the next 40 years and this number will be 2 times in Iran, as well as the population of 60 will be around 10 million years until the year 2020 and 2050 to more than 26 million people (2). Increasing age is associated with increasing the risk of metabolic syndrome (3). Due to change in life style, the prevalence of metabolic syndrome in today's society has increased (4). Metabolic syndrome can have a negative effect on physical performance, mental state, personal, familial and social relationships, and general health and feeling of well-being of patients. Metabolic syndrome was defined according to the criteria of the NCEP/ATP III to include individuals with any three or more of the following five components:(1) Waist circumference $>94 \mathrm{~cm}$; (2) high TG $\geq 150 \mathrm{mg} / \mathrm{dl}$; (3) low HDL-C $<40 \mathrm{mg} / \mathrm{dl}$; (4) high blood pressure (systolic BP $\geq 130 \mathrm{~mm} \mathrm{Hg}$ or diastolic BP $\geq 85 \mathrm{~mm} \mathrm{Hg}$ or treatment of hypertension, and (5) high FBG $\geq 6.1 \mathrm{mmol} / \mathrm{L}(4,5)$ Stress caused by social issues and the absence of a family member leads to increase in anxiety and worry in the 
person (6). Chronic anxiety and the stress caused by the society cause bulimia and the cause of metabolic syndrome (7). Diseases are the cause of increasing stress and cause anxiety. The results of some fundamental research such as Carroll et al. (2009), and Kai et al. (2015) refers to the positive relationship between anxiety and metabolic syndrome $(8,9)$. In another study, there has been a relationship between anxiety and metabolic syndrome indexes. In particular, they noted a strong relationship between the size of waist cercomfrences, triglyceride and blood pressure (10). While Takeuchi et al. (2009) refers to the presence of a positive and meaningful (significantly) relationship between depression and metabolic syndrome and lack of meaningful (significantly) relationship with metabolic syndrome (11). The research of Vogelzangs et al. (2007) noted that anxiety in old men was significantly related to metabolic syndrome, which was not significant in women, and the cause of lack of meaningful (significantly) relationship was related to the impact of the stress which caused by the society which women experience this problem less than men. The question is suggested whether social stress is associated with metabolic syndrome or other variables in that role (12). We will review the research history that has examined the impact of exercise on anxiety reduction. Kargarfard et al. (2011) examined the effect of eight weeks of training on the anxiety of hemophilia patients (13). Salehpoor et al (2015) studied the effect of exercise on the anxiety of young people who had mental disorders (14). Also, Sardari et al. (2009) investigated the effect of 8 weeks of aerobic training on anxiety in patients with type 2 diabetes (15). Given that the previous research has examined the impact of exercise training on anxiety in people with different diseases and so far, there was no research that examined the effect of exercise on anxiety in patients with metabolic syndrome and since the prevalence of metabolic syndrome is much more than other fears. It is a high importance for the research to eliminate the physical and mental problems of these patients.

An increasing number of studies confirm that oxidative stress, chronic inflammation and angiogenesis all play important roles in the pathogenesis of MS. Chronic hyperglycemia causes oxidative stress in tissues prone to complications in patients with diabetes (16). Oxidative stress occurs in a cellular system when the production of free radical moieties exceeds the antioxidant capacity of that system. If cellular antioxidants do not remove free radicals, radicals attack and damage proteins, lipids, and nucleic acids. The oxidized or nitrosylated products of free radical attack have decreased biological activity, leading to loss of energy metabolism, cell signaling, transport, and other major functions. These altered products are also targeted for proteosome degradation, further decreasing cellular function. Accumulation of such injury ultimately leads a cell to die through necrotic or apoptotic mechanisms. In conclusion, a puzzle of many pieces of evidence suggests that free radical overgeneration may be considered the key in the generation of insulin resistance, diabetes, and cardiovascular disease (16).

Stachys lavandulifolia (S. lavandulifolia) is an aromatic plant belonging to the Labiatae family. In Iran, S. lavandulifoliais is widely found in Azerbaijan, Golestan, Khorasan, Mazandaran, and Tehran (17). The plant contains large amounts of flavonoids (17). The antibacterial, antitoxic, antihepatitis, hypotensive, and antianxiety properties of different Stachys species' extracts have previously been documented in a line of pharmacological studies. In Iranian folk medicine, the aerial parts of this plant have been used as an analgesic and an antiinflammatory (18). In normal human life, environmental pollutants, stress, and 
different diseases cause oxidative stress that results in the damage of biomolecules such as proteins, lipids, amino acids and nucleic acids. Therefore, to prevent cell injuries the body defends itself by means of enzymatic or non-enzymatic antioxidants. Enzymes such as superoxide dismutase, glutathione peroxidase, and catalase and nonenzymatic ones such as vitamin E, carotenoids, ascorbic acid, and bilirubin play a role (18). Factors such as environmental pollutants disturb the balance between formation and elimination of free radicals and, as a result, oxidative stresses occur that are considered to cause many diseases such as cancers and diabetes as well as contributing to the aging process (17-18). In previous studies the antioxidant potentiality of the aerial components of $\mathrm{S}$. lavandulifolia has been reported (17-18).

The present study aimed to investigate the effect of an twelve months aerobic exercise program and aqueous extract of S. lavandulifolia on the anxiety, Glutathione, Malondialdehyde and Metabolic Syndrome Profiles in women with metabolic syndrome.

\section{Materials And Methods}

\section{Participants}

The research method was a semi-experimental type with before-after design. The subjects were 48 females with metabolic syndrome ages aged 60-65 years who were purposively selected among all females with metabolic syndrome. This research was conducted according to the guidelines laid down in the Declaration of Helsinki and was approved by the ethics committees of Semnan University of Medical Sciences and Health Services (IR.SEMUMS.REC.1396.107). Then, the subjects were randomly divided into four groups: exercise $(n=12)$, exercise $+S$. lavandulifolia $(n=12), S$. lavandulifolia $(n=12)$ and control group $(n=12)$. Prior to beginning training intervention, subjects completed medical questionnaire and written consent was taken from them. In the same session, anthropometric measurements (height, weight) and body composition were measured using Body composition analyzer (Olympia model 3/3 Javan Company, South Korea).

\section{Metabolic Syndrome Definition}

Metabolic syndrome was defined according to the criteria of the NCEP/ATP III to include individuals with any three or more of the following five components: (1) Waist circumference $>94 \mathrm{~cm}$; (2) high TG $\geq 150$ $\mathrm{mg} / \mathrm{dl}$; (3) low HDL-C < $40 \mathrm{mg} / \mathrm{dl}$; (4) high blood pressure (systolic BP $\geq 130 \mathrm{~mm} \mathrm{Hg}$ or diastolic BP $\geq 85$ $\mathrm{mm} \mathrm{Hg}$ or treatment of hypertension, and (5) high FBG $\geq 6.1 \mathrm{mmol} / \mathrm{L}(5)$.

\section{Exercise protocol}

Each subject walked or ran at $65-75 \%$ heart rate reserve (HRR) on a treadmill for $3 \cdot 12-17 \mathrm{~min}$. Over the 12- months treatment, each week, one minute was added to each set, beginning with 8 minutes, so that the duration of each training set at the 12 week was 19 minutes. After the 12 weeks, the training set times did not change. Each session consisted of three sets of consecutive sessions with a 5-minute rest interval 
between the sets. Heart Rate was monitored during the test using heart rate monitoring devices (Polar M400; Finland).

\section{Preparation of the plant material}

Dried and powdered aerial parts of the plant ( $3 \mathrm{~g})$ (19) were macerated with $500 \mathrm{ml}$ of ethanol and water (8:2). The extract was concentrated in a rotating evaporator under reduced pressure to give a residue $(13.6 \mathrm{~g})$. The residue was dissolved in normal saline for final suitable concentrations. The extraction of the essential oil was performed by hydrodistillation of the herb in a Clevenger-type apparatus, according to the method recommended in British Pharmacopoeia.

\section{Measurement of biochemical parameters}

All participants were 50-65 years old women with metabolic syndrome. A separate questionnaire was prepared for each subject and they were asked to record their diet during the experiment. A before after trial was done. A five $\mathrm{ml}$ of blood sample was taken at the beginning and the end of the study from each individual assigned to consume $3 \mathrm{~g}$ of the $\mathrm{S}$. lavandulifolia infusion twice daily at the morning and the evening. Afterwards, blood samples were centrifuged and their serum separated and analyzed for oxidative stress parameters.

The thiobarbituric acid (TBA) method was used to measure lipid peroxidation. As a result of free radical attack, different aldehydes such as malondialdehyde (MDA) are produced from lipids that react with TBA under acidic conditions and high temperatures. The resultant complex has a maximum absorbance at $532 \mathrm{~nm}$. To evaluate lipid peroxidation, serum proteins were initially precipitated with the addition of 2.5 $\mathrm{ml}$ TBA to $0.5 \mathrm{ml}$ serum and kept for 10 minutes at room temperature. The mixture was subsequently centrifuged at $3000 \mathrm{~g}$ for 10 minutes, the supernatant removed, and the precipitate washed with $0.5 \mathrm{M}$ sulfuric acid. After wards, $2.5 \mathrm{ml}$ of $0.5 \mathrm{M}$ sulfuric acid and $3 \mathrm{ml}$ of a $0.2 \%$ TBA solution were added to each tube. After preparation of the $3 \mathrm{ml} 0.2 \%$ TBA solution and $2.5 \mathrm{ml}$ of each standard, all samples other than these solutions were incubated in a $100^{\circ} \mathrm{C}$ water bath for 30 minutes. Subsequently, $4 \mathrm{ml} \mathrm{n}$-buthanol was added to each cold tube and mixed well by vigorous vortexing. Finally, the mixture was centrifuged at $3500 \mathrm{~g}$ for 10 minutes and the absorbance of the supernatant recorded at $532 \mathrm{~nm}(20)$.

The activity of the Catalase (cat) enzyme was evaluated based on changes in the concentration of hydrogen peroxide $(10 \mathrm{ml})$ at a wavelength of $240 \mathrm{~nm}$ and according to the Aebi method (21). In this method, the Cat enzyme in the serum sample decomposed hydrogen peroxide, leading to reduced absorption of this substance at a wavelength of $240 \mathrm{~nm}$ over a period of 2 minutes. And from the difference of absorption240 A $\Delta$ per unit time, enzyme activity was calculated using standard curve. The amount of enzyme that breaks down the amount of one micromole of hydrogen peroxide at $\mathrm{pH}$ of 7 and the temperature of $25^{\circ} \mathrm{C}$ was considered to be one unit of enzyme activity. On the other hand, the activity of Gpx was calculated using the following formula and Beer-Lambert's law (22). 
The OxiSelect ${ }^{\text {TM }}$ Total Glutathione Assay Kit is a quantitative assay for measuring the total glutathione content within a sample (GSH/GSSG). Glutathione Reductase reduces oxidized glutathione (GSSG) to reduced glutathione (GSH) in the presence of NADPH. Subsequently, the chromogen reacts with the thiol group of GSH to produce a colored compound that absorbs at $405 \mathrm{~nm}$. The total glutathione content in unknown samples is determined by comparison with the predetermined glutathione standard curve. The rate of chromophore production is proportional to the concentration of glutathione within the sample. The rate can be determined from the absorbance change over time. Metaphosphoric acid is provided to remove interfering proteins or enzymes from samples (23).

Fasting venous blood samples were taken from the antecubital vein 24 hours before (Fasting blood samples were taken at 9am) and after exercise (It should be noted, however, that in order to eliminate the acute effects of exercise such as delayed fatigue and possible minor damage to muscle structure on blood variables, post-test blood sampling was performed four days after the last training session) (24, 25).

For measuring serum blood markers, the samples were allowed to clot for $30 \mathrm{~min}$ at room temperature and then centrifuged at $3000 \mathrm{rpm}$ for $10 \mathrm{~min}$ at $4^{\circ} \mathrm{C}$. Obtained serums were dispensed into micro tubes and stored at $-80^{\circ} \mathrm{C}$ until the measurement of blood parameters. For measuring plasma blood markers, blood samples collected into tubes containing ethylene diamine tetra acetic acid (EDTA) were immediately centrifuged and stored at $-80^{\circ} \mathrm{C}$ until the assay.

Blood glucose levels were measured by glucose oxidase method and fat levels were measured by standard enzymatic method using Kobas Mira model biochemical autoanalysis device.

\section{Beck Anxiety Inventory (BAl)}

The BAl is a short list describing 21 anxiety symptoms such as "wobbliness in legs", "scared" and "fear of losing control". Respondents are asked to rate how much each of these symptoms bothered them in the past week, on a scale ranging from 0 (not at all) tot 3 (severely, I could barely stand it). The total score has a minimum of 0 and a maximum of 63 . The scale was validated in a sample of 160 psychiatric outpatients with various anxiety and depressive disorders, diagnosed with the Structured Clinical Interview for DSM-III. The BAI has a high internal consistency (Cronbachs $\mathrm{a}=.92$ ) and a test-retest reliability over one week of .75(26).

\section{How to calculate body fat percentage}

The body fat percentage of the subjects was calculated using the German-made OMRON BF500 body composition.

\section{How to calculate caloric intake}

Subjects were recorded daily food intake on the note sheet and food consumed at breakfast, snack, lunch and dinner was calculated by N4 software.

\section{Statistical analysis}


Data were presented as mean \pm SD. The normal distribution of data was examined by KolmogorovSmirnov test and homogeneity of variances was studied by Levin's test. Intergroup comparison was performed by dependent t-test and between-group comparison was done by one-way ANOVA and ANCOVA. In the case of significance, the Bonferroni follow-up test was applied. $\mathrm{P} \leq 0.05$ was considered significant. Data analysis was performed using SPSS version 24 software.

\section{Results}

The results of the pretest showed no significant difference in body weight, BMI, WHR, SBP, anxiety, Triglyceride, HDL, Glucose, MDA, GSH and CAT among the study groups $(P>0.05)$.

The results of the posttest indicated a significant reduction in the mean body weight, BMI, WHR, SBP, anxiety, Triglyceride, HDL and Glucose in the exercise group $(P \leq 0.05)$, $S$. lavandulifolia group $(P \leq 0.05)$, and exercise $+S$. lavandulifolia group $(P \leq 0.05)$. The findings of ANCOVA test showed a significant difference among the study groups in the body weight, BMI, WHR, SBP, anxiety, Triglyceride, HDL and Glucose $(P \leq 0.05)$ so that a significant decrease was observed in the body weight, BMI, WHR, SBP, anxiety, Triglyceride, HDL and Glucose between the control group with exercise $(P \leq 0.05), S$. lavandulifolia $(P \leq 0.05)$, and exercise $+S$. lavandulifolia $(P \leq 0.05)$ groups. Moreover, the exercise $+S$. lavandulifolia groups showed a significantly higher body weight, BMI, WHR, SBP, anxiety, Triglyceride, HDL and Glucose than the exercise and S. lavandulifolia groups $(P \leq 0.000)($ Table 1$)$.

Table 1. The anthropometric indices, body composition of subjects before and after the study 


\begin{tabular}{|c|c|c|c|c|c|}
\hline \multirow[t]{2}{*}{ Variable } & \multirow[t]{2}{*}{ group } & pre-test & Post-test & P-value & P-value \\
\hline & & Mean \pm SD & Mean \pm SD & $\begin{array}{l}\text { Within- } \\
\text { group }\end{array}$ & $\begin{array}{l}\text { Between- } \\
\text { group }\end{array}$ \\
\hline \multirow{4}{*}{ Weight (kg) } & Exercise & $80.04 \pm 06.43$ & $70.83 \pm 04.04$ & 0.003 & \multirow{4}{*}{$0.004^{e}$} \\
\hline & $\begin{array}{l}\text { Exercise+ S. } \\
\text { lavandulifolia }\end{array}$ & $81.13 \pm 04.41$ & $68.68 \pm 06.12$ & 0.0000 & \\
\hline & S. lavandulifolia & $80.71 \pm 07.21$ & $69.75 \pm 03.02$ & 0.001 & \\
\hline & Control & $79.08 \pm 07.73$ & $80.88 \pm 09.68$ & 0.341 & \\
\hline \multirow{4}{*}{$\mathrm{BMI}(\mathrm{kg} / \mathrm{m} 2)$} & Exercise & $33.63 \pm 04.54$ & $27.43 \pm 03.62$ & 0.009 & \multirow{4}{*}{$0.008^{\mathrm{e}}$} \\
\hline & $\begin{array}{l}\text { Exercise+ S. } \\
\text { lavandulifolia }\end{array}$ & $34.69 \pm 05.61$ & $26.73 \pm 04.77$ & 0.000 & \\
\hline & S. lavandulifolia & $33.56 \pm 07.63$ & $27.24 \pm 05.73$ & 0.008 & \\
\hline & Control & $34.49 \pm 05.38$ & $34.32 \pm 08.35$ & 0.231 & \\
\hline \multirow{4}{*}{ WH R } & Exercise & $104.78 \pm 05.32$ & $93.52 \pm 03.61$ & 0.01 & \multirow{4}{*}{$0.006^{e}$} \\
\hline & $\begin{array}{l}\text { Exercise+ S. } \\
\text { lavandulifolia }\end{array}$ & $102.56 \pm 06.43$ & $92.63 \pm 03.67$ & 0.008 & \\
\hline & S. lavandulifolia & $103.42 \pm 05.56$ & $93.63 \pm 02.43$ & 0.02 & \\
\hline & Control & $103.98 \pm 04.84$ & $104.21 \pm 05.75$ & 0.542 & \\
\hline \multirow{4}{*}{$\mathrm{SBP}(\mathrm{mmHg})$} & Exercise & $158.37 \pm 07.32$ & $121.43 \pm 3.71$ & 0.008 & \multirow{4}{*}{$0.007^{e}$} \\
\hline & $\begin{array}{l}\text { Exercise+ } \mathrm{S} \text {. } \\
\text { lavandulifolia }\end{array}$ & $160.37 \pm 06.61$ & $120.43 \pm 2.99$ & 0.000 & \\
\hline & S. lavandulifolia & $157.36 \pm 06.76$ & $122.43 \pm 2.87$ & 0.005 & \\
\hline & Control & $161.26 \pm 05.63$ & $159.87 \pm 07.58$ & 0.128 & \\
\hline \multirow{4}{*}{ Anexiety } & Exercise & $24.05 \pm 64.76$ & $09.06 \pm 84.24$ & 0.009 & \multirow{4}{*}{$0.003^{\mathrm{e}}$} \\
\hline & $\begin{array}{l}\text { Exercise+ } \mathrm{S} \text {. } \\
\text { lavandulifolia }\end{array}$ & $23.99 \pm 04.98$ & $07 . \pm 8404.24$ & 0.000 & \\
\hline & S. lavandulifolia & $24.87 \pm 06.67$ & $09.77 \pm 07.98$ & 0.005 & \\
\hline & Control & $25.06 \pm 25.33$ & $24.07 \pm 78.91$ & 0.213 & \\
\hline \multirow{4}{*}{$\begin{array}{l}\text { Triglyceride } \\
(\mathrm{mg} / \mathrm{dl})\end{array}$} & Exercise & $256.32 .73 \pm 34$ & $142.82 \pm 11.89$ & 0.01 & \multirow{4}{*}{0.008} \\
\hline & $\begin{array}{l}\text { Exercise+ } \mathrm{S} \text {. } \\
\text { lavandulifolia }\end{array}$ & $264.08 \pm 45.53$ & $141.98 \pm 12.11$ & 0.008 & \\
\hline & S. lavandulifolia & $256.32 \pm 74.34$ & $144.54 \pm 12.63$ & 0.02 & \\
\hline & Control & $\begin{array}{l}264.08 \pm 45.53 \\
\text { Page } 8 / 17\end{array}$ & $260.87 \pm 68.74$ & 0.342 & \\
\hline
\end{tabular}




\begin{tabular}{|c|c|c|c|c|c|}
\hline \multirow{4}{*}{$\mathrm{HDL}(\mathrm{mg} / \mathrm{dl})$} & Exercise & $41.36 \pm 12.45$ & $53.47 \pm 04.82$ & 0.009 & \multirow{4}{*}{0.001} \\
\hline & $\begin{array}{l}\text { Exercise+ S. } \\
\text { lavandulifolia }\end{array}$ & $41.86 \pm 11.56$ & $54.56 \pm 09.56$ & 0.000 & \\
\hline & S. lavandulifolia & $42.34 \pm 10.37$ & $54.89 \pm 08.66$ & 0.005 & \\
\hline & Control & $45.23 \pm 04.46$ & $46.64 \pm 06.84$ & 0.421 & \\
\hline \multirow{4}{*}{ Glucose (mg/dl) } & Exercise & $182.84 \pm 32.65$ & $115.63 \pm 10.73$ & 0.009 & \multirow{4}{*}{0.000} \\
\hline & $\begin{array}{l}\text { Exercise+ S. } \\
\text { lavandulifolia }\end{array}$ & $183.98 \pm 31.87$ & $114.65 \pm 11.01$ & 0.000 & \\
\hline & S. lavandulifolia & $182.54 \pm 30.43$ & $113.65 \pm 12.06$ & 0.005 & \\
\hline & Control & $174.58 \pm 42.27$ & $170.98 \pm 64.03$ & 0.654 & \\
\hline \multirow{4}{*}{$\begin{array}{l}\text { Glutathione }(\mu \mathrm{mol} \\
\text { / I) }\end{array}$} & Exercise & $46.85 \pm 2.04$ & $41.78 \pm 0.66$ & 0.15 & \multirow{4}{*}{$\begin{array}{l}0.002^{*} a, \\
b\end{array}$} \\
\hline & $\begin{array}{l}\text { Exercise+ S. } \\
\text { lavandulifolia }\end{array}$ & $42.19 \pm 0.77$ & $45.67 \pm 0.73$ & $0.006^{*}$ & \\
\hline & S. lavandulifolia & $42.75 \pm 0.98$ & $43.36 \pm 1.06$ & $0.001^{*}$ & \\
\hline & Control & $43.73 \pm 1.76$ & $43.01 \pm 1.29$ & 0.74 & \\
\hline \multirow{4}{*}{$\begin{array}{l}\text { Malondialdehyde } \\
(\mu \mathrm{mol} / \mathrm{l})\end{array}$} & Exercise & $3.02 \pm 0.21$ & $3.7 \pm 0.054$ & $0.004^{*}$ & \multirow{4}{*}{$\begin{array}{l}0.001^{*} a, \\
b, c, d\end{array}$} \\
\hline & $\begin{array}{l}\text { Exercise+ } \mathrm{S} \text {. } \\
\text { lavandulifolia }\end{array}$ & $3.49 \pm 0.14$ & $2.63 \pm .0 .08$ & $0.009 *$ & \\
\hline & S. lavandulifolia & $3.13 \pm 0.32$ & $2.93 \pm 0.3$ & 0.18 & \\
\hline & Control & $3.09 \pm 0.15$ & $3.07 \pm 0.17$ & 0.45 & \\
\hline \multirow{5}{*}{$\begin{array}{l}\text { Catalase } \\
(\mu \mathrm{mol} / \mathrm{ml} / \mathrm{min})\end{array}$} & Exercise & $0.21 \pm 0.01$ & $0.32 \pm 0.04$ & 0.14 & \multirow{5}{*}{$0.02 * d$} \\
\hline & & & & & \\
\hline & $\begin{array}{l}\text { Exercise+ S. } \\
\text { lavandulifolia }\end{array}$ & $0.22 \pm 0.006$ & $0.41 \pm 0.02$ & $0.001^{*}$ & \\
\hline & S. lavandulifolia & $0.17 \pm 0.004$ & $0.32 \pm 0.04$ & $0.019 *$ & \\
\hline & Control & $0.2 \pm 0.01$ & $0.1 \pm 0.04$ & 0.81 & \\
\hline
\end{tabular}

BMI, Body Mass Index; WHR, waist hip ratio, SBP; Systolic Blood Pressure; HDL, High-density lipoprotein, 1. $a$ is Significant between the exercise group and the Exercise+ $S$. lavandulifolia, 2 . b is Significant between the exercise group and the S. lavandulifolia, 3. c is Significant between the exercise group and control, 4. $d$ is Significant between the Exercise+ S. lavandulifolia group and control, 5. e is Significant between the Exercise, Exercise $+\mathrm{S}$. lavandulifolia and S. lavandulifolia groups with control

Based on paired t-test (the results are shown in Table 1, MDA index significantly increased in the exercise group ( $P=0.004)$ and non-significant change in antioxidant indices (CAT and GSH indices) was observed 
in the exercise groups after the 12-months training period $(P \geq 0.05)$. In the $S$. lavandulifolia group, there was a significant increase in CAT $(P=0.019)$ and $G S H(P=0.001)$ While no significant changes were observed in MDA $(P \geq 0.05)$. In the exercise- $S$. lavandulifolia group, there was a significant increase in CAT $(P=0.001)$ and GSH $(P=0.006)$ and MDA decreased significantly $(P=0.009)$. Based on One-way analysis of variance, there was between-group change at the serum levels of CAT, GSH, and MDA (P $\leq$ 0.05). Also, the CAT index showed a significant increase in the exercise- $\mathrm{S}$. lavandulifolia group compared to the control group and GSH index increased significantly in the two groups of exercise- S. lavandulifolia and $S$. lavandulifolia compared to the exercise group $(P \leq 0.05)$.

\section{Discussion}

The results of this study showed that 12 months of aerobic exercise significantly increased serum levels of MDA as lipid destruction index in overweight girls. Several studies have shown a significant increase in lipid peroxidation and serum levels of MDA following intense aerobic exercise, which the results of this study are in line with the results of the mentioned studies. (27). Free radicals react with phospholipid layers of the cell membrane and result in cellular degradation. As a result of this reaction, measurable products are released, most notably malondialdehyde (28). Research has shown that lipid peroxidation and cell membrane degradation are affected by various factors such as exercise intensity (29).

results of the present study regarding changes in malondialdehyde levels were inconsistent with the results of some studies in this area (28). As Gupta et al. (2015) examined the effect of three weeks of regular aerobic training, MDA decreased in healthy subjects (30). Research has shown that obesity is associated with increased oxidative stress, and in obese individuals, the production of free radicals increases and the antioxidant system is weakened (31). Amirkhizi et al. (2012) indicated that the mean plasma concentrations of MDA in women with overweight and obesity were significantly higher than those with normal weight (32). Consequently, the reason for the inconsistency of the present study with Gupta is the higher levels of MDA in overweight people also the difference in the type of exercise. Soares et al. (2015) also examined the indexes related to oxidative stress in non-athlete subjects that 16 weeks of physical activity was associated with an increase in antioxidant activity and a decrease in MDA levels (33).

In the present study, levels of GSH, and CAT in two groups of S. lavandulifolia users showed a significant increase compared to pre-test. MDA showed a significant decrease respectively in S. lavandulifolia group, this is consistent with results of several studies (34). Taking the results collectively, treatment with the aerial parts of $\mathrm{S}$. lavandulifolia led to a considerable reduction in oxidative stress. In support of this finding, the antioxidant potential of numerous Stachys species, including S. lavandulifolia, has been reported by other investigators (28), but this is the first trial in human. Oxidative stress plays a major role in the pathogenesis or progress of many debilitating diseases or conditions in humans such as osteoporosis (32), diabetes (33), islet transplantation, inflammatory bowel diseases, preeclampsia, pancreatitis, metaltoxicity, or pesticide poisoning (28-33). The results of the present study are optimistic and show marked antioxidant activity of the S.lavandulifolia extract in healthy individuals. Therefore, $\mathrm{S}$. 
lavandulifolia can be used as a supplement to protect individuals from oxidative stresses in the abovementioned diseases.

In previous investigations of Stachys species, the presence of various polyphenol compounds was reported. In methanol and ethanol extract of aerial parts of this genus, apigenin, chrysoeriol, forsithoside B, caffeic, sinapic, protocatechuic, chlorogenic and rosmarinic acids were identified. Some of theses compounds were assessed on their antioxidant activity earlier. Most of the major constituents of the essential oil of stachys species were piperitenone, hexadecanoic acid, germacrene $D$, -pinene, 4-hydroxy-4methyl-2- pentanone, beta caryophyllene, limonene, pulegone, bicyclogermacrene, -pinene, spathulenol, carvacrol and eugenol (35). However, the genus Stachys has been the subject of some phytochemical studies. Flavonoids, phenyl ethanoid glycosides, phenolic acids, iridoids, monoterpenes, sesquiterpenes, diterpenes, and triterpene saponins have been reported to be present in different Stachys species. Stachys lavandulifolia has also been reported to contain volatile oil and a phenyl propanoid glycoside (35).

Taking the results collectively, treatment with the aerial parts of S. lavandulifolia led to a considerable reduction in oxidative stress. In support of this finding, the antioxidant potential of numerous Stachys species, including S. lavandulifolia, has been reported by other investigators (36), but this is the first trial in human. Oxidative stress plays a major role in the pathogenesis or progress of many debilitating diseases or conditions in humans such as osteoporosis (36), diabetes (36), islet transplantation (36), inflammatory bowel diseases (36), preeclampsia (36), pancreatitis (36), metaltoxicity (36), or pesticide poisoning (36). The results of the present study are optimistic and show marked antioxidant activity of the S.lavandulifolia extract in healthy individuals.

The American Diabetes Association recommended the intensity and duration of physical activity in this study in 2002, which recommended aerobic exercise with a intensity of 50 to $80 \%$ of the maximum aerobic power in three to four weeks (37).

Based on the findings, anxiety was significantly reduced after 12 months of aerobic exercisemand consumption of $S$. lavandulifolia (P凶0.05).

The results of the investigation of Smits et al. (2008), Broman et al. (2008), Andreas et al. (1998), Kargarfard et al. (2011), Salehpour et al. (2015) and Salehpoor et al. (2015) were consistent whith the result of present research $(13-15,38,39)$. Considering that several fundamental studies have pointed out the relationship between anxiety and metabolic syndrome $(8-10,12) 6$ none of the existing research has the effect of aerobic exercise on anxiety and metabolic syndrome. For example, Smits et al. (2008) pointed out that exercise with a intensity of $70-90 \%$ of the maximum heart rate for 20 minutes and three times per week significantly reduces anxiety (38). Also Broman et al. (2008) had reported 20 minutes of exercise was effective in reducing anxiety in people who had more anxiety intensity than 28 (40). Andreas and associates (1998) reported 10 weeks of aerobic training effective in reducing severe anxiety (41). Kargarfard and associates (2011) examined the effect of eight weeks of training on the anxiety of hemophilia patients (13). Salehpoor et al. (2015) examined the effect of training on the anxiety of young 
people who had mental disorders (14). Also Sardari et al. (2007) investigated the effect of 8 weeks of aerobic training on anxiety in patients with type 2 diabetes (15). Considering that there is still no precise mechanism regarding the effects of exercise in improving anxiety, it is likely that the cause of anxiety reduction in the impact of exercise on the development of overall health and fitness and increasing social relationships of individuals $(13,15,38-39)$.

The causes of anxiety seem to be different at every stage of life. Martyr wives early due to stress and anxiety caused by social issues and concerns for the success of the children suffered alone. It can be said that the cause of metabolic syndrome is related to chronic anxiety of martyr's wives. Given that at this stage in the life of all the offspring are in good working and social positions, the cause of stress and anxiety of their can no longer be related to it. Most likely, the metabolic syndrome and the relative lack of health are the cause of anxiety for martyr's wives. Due to the increasing level of knowledge and awareness of the type of disease and their importance in anxiety, we can mention metabolic syndrome as the cause of current anxiety of martyr's wives. Aerobic exercise for 12 months with moderate intensity significantly reduced blood glucose, blood pressure, waist circumference, triglyceride, body fat percentage and BMI of 50-65 year old martyrs' wives. Reduced Blood glucose, blood pressure, waist circumference, triglyceride, body fat percentage, and BMI were significantly associated with reduced anxiety. On the other hand, increased endorphin secretion through regular exercise, which has a positive effect on relief, relaxation and happiness, may be one of the reasons for decreased anxiety.

\section{Conclusions}

The results of this study showed that 12 months of aerobic exercise caused a significant increase in MDA as an indicator of lipid degradation and a lack of change in serum antioxidant levels of GSH and CAT. Since aerobic exercise and S. lavandulifolia consumption caused a significant reduction of MDA serum levels and a significant increase in CAT and GSH. Therefore, exercise combined with taking S. lavandulifolia consumption has unique antioxidant properties.

improvement of metabolic syndrome after 12 months of moderate intensity exercise and S. lavandulifolia consumption, they can be attributed to the reduction of anxiety and it can be suggested that aerobic exercises $+\mathrm{S}$. lavandulifolia consumption as a non-invasive strategy in the treatment of anxiety in women aged 65 - 50 years with metabolic syndrome. So it is recommended that with metabolic syndrome people, take $S$. lavandulifolia consumption along with moderate intensity exercises.

\section{Abbreviations}

AT: Aerobic Exercise Training

MetS: Metabolic Syndrome

SBP: systolic blood pressure 
BMI: Body Mass Index

WHR: waist hip ratio

CAT: Catalase

MDA: Malondialdehyde

GSH: Glutathione

\section{Declarations}

\section{Authors contributations}

The study was designed by $\mathrm{AO}$; data were collected and analyzed by $\mathrm{AO}$; data interpretation and manuscript preparation were undertaken by $\mathrm{AO}$. The author read and approved the final manuscript.

\section{Funding}

This article is taken from research project number 97/I/ER/1920, sponsored by University of Bonab, Iran.

\section{Avialability of data and materials}

Not applicable. Conclusions of the manuscript are based on relevant data sets available in the manuscript.

\section{Ethics approval and consent to participate}

Bonab University Review Board for the protection of human subjects (Approval date, 2018-July-17) approved this study.

\section{Consent for publication}

All participants were aware during the informed consent process that the results of this study may be published.

\section{Competing interests}

The authors declare that they have no competing interests.

\section{Publisher's Note}

Springer Nature remains neutral with regard to jurisdictional claims in published maps and institutional affiliations.

\section{Contributions}


The study was designed by $\mathrm{OA}$; data were collected and analyzed by $\mathrm{OA}$; data interpretation and manuscript preparation were undertaken by $A R$.

\section{Acknowledgements}

We thank to all the subjects who volunteerly participated and we also gratefaly thank dear president of Martyr Foundation and Sacrifice Affairs who sincerely helped us in this research.

\section{References}

1. Alipour F, Sajadi H, Forouzan A, Biglarian A, Jalilian A. Quality of life in elderly region 2 Tehran. Iranian journal of ageing [in Persian]. 2008;3(10):75-83.

2. Sharifzadeh GH, Moudi M, Akhbari S.H. Investigating health status of older people supported by imam Khomeini. Iranian journal of ageing. 2010;3(7):52-60.

3. Sérgio Gomes da Silva, Priscila Santos Rodrigues Simões, Renato Arruda Mortara, Fulvio Alexandre Scorza, Esper Abrão Cavalheiro, Maria da Graça Naffah-Mazzacoratti, et al. Exercise-induced hippocampal anti-inflammatory response in aged rats. Neuroinflammation. 2013;10:61.

4. Cavalieri M, Ropele S, Petrovic K, Pluta-Fuerst A, Homayoon N, Enzinger C, et al. Metabolic syndrome, brain magnetic resonance imaging, and cognition. Diabetes Care. 2010;33(12):2489-95.

5. Grundy SM, Cleeman JI, Daniels SR, Donato KA, Eckel RH, Franklin BA, et al. Diagnosis and management of the metabolic syndrome: an American heart association/national heart, lung, and blood institute scientific statement. Circulation. 2005;112:2735-52.

6. Aline Sardinha, Antonio E Nardi. The Role of Anxiety in Metabolic Syndrome. Endocrinol Metab. 2012;7(1):63-71.

7. Arce M, Michopoulos V, Shepard KN, Ha QC, Wilson ME. Diet choice, cortisol reactivity, and emotional feeding in socially housed rhesus monkeys. Physiol Behav. 2010;101(4):446-55.

8. Carroll D, A. C. Phillips, G. N. Thomas, C. R. Gale, I. Deary, G. D. Batty. Generalized anxiety disorder is associated with metabolic syndrome in the Vietnam experience study. Biol Psychiatry. 2009;66:91-3.

9. Kai G. Kahl, Ulrich Schweiger, Christoph Correll, Conrad M€uller, Marie-Luise Busch, Michael Bauer, et al. Depression, anxiety disorders, and metabolic syndrome in a population at risk for type 2 diabetes mellitus. Brain and Behavior. 2015;5(3):1-7.

10. van Reedt Dortland, A. K, E. J. Giltay, T. van Veen, F. G. Zitman, B. W. Penninx. Metabolic syndrome abnormalities are associated with severity of anxiety and depression and with tricyclic antidepressant use. Acta Psychiatr Scand. 2010;122:30-9.

11. Takeuchi T, Nakao M, Nomura K YE. Association of metabolic syndrome with depression and anxiety in Japanese men. Diabetes Metab. 2009 35(1):32-6.

12. Nicole Vogelzangs, Aartjan T. F. Beekman, Stephen B. Kritchevsky, Anne B. Newman, Marco Pahor, Kristine Yaffe, et al. Psychosocial risk factors and the metabolic syndrome in elderly persons: findings from the health, aging and body composition study. J Gerontol. 2007;62(5):563-9. 
13. Mehdi Kargarfard, Mehdi Dehghani, Heidari A. Effect of a period of aquatic exercise therapy on the quality of life, anxiety and depression in patients with hemophilia. koomesh. 2011;4:364-72.

14. Masoomeh Salehpoor, Mohsen Salesi, Ghorban Hemati Alamdarloo. The Effect of Exercise on Anxiety of Adolescents with Intellectual Disability. physical treatments. 2015;5(1):25-32.

15. Sardar M, Sohrabi M, Shamsian A, Aminzadeh R. Effects of Aerobic Exercise training on the Mental and Physical Health and Social Functioning of Patients with Type 2 Diabetes Mellitus. Iranian Journal of Endocrinology and Metabolism. 2009;11(3):251-6.

16. Soleiman Mahjoub, and Jila Masrour-Roudsari Role of oxidative stress in pathogenesis of metabolic syndrome. Caspian J Intern Med. 2012; 3(1): 386-396.

17. Háznagy-Radnai E, CzigleS, Zupkól, Falkay G, Máthel. Comparison of antioxidant activity in enzymeindependent system of six Stachys species. Fitoterapia. 2006; 77(7-8): 521-524. 3.

18. Hajhashemi V, Ghanndi A, Sedighifar S. Analgestic and anti-inflammatory properties of the hydroalcoholic, poly phenolic and boiled extracts of Stachy slavandulifolia. Res Pharm Sci. 2007; 2: 92-98.

19. Rahzani K, Malekirad AA, Zeraatpishe A, Hosseini N, Seify SMR, Abdollahi M. Anti-oxidative stress activity of Stachys lavandulifolia aqueous extract in humans. Cell J. 2013;14(4):314-317.

20. Esterabauer $\mathrm{H}$, Cheeseman $\mathrm{KH}$. Determination of aldehydic lipid peroxidation products: malonaldehyde and 4-hydroxynonenal.Methods Enzymol. 1990; 186: 407-421.

21. Aebi H. Catalase in vitro. InMethods in enzymology. 1984 ;. 105, pp. 121-126). Academic Press.

22. Ursini F, Maiorino M, Gregolin C. The selenoenzyme phospholipid hydroperoxide glutathione peroxidase. Biochimica et Biophysica Acta (BBA)-General Subjects. 1985;839(1):62-70.

23. Wardhani, B.W.K. et al. (2020). Antifibrotic Activity of Phaleria macrocarpa Extract in Rat Liverfibrosis Model: Focus on Oxidative Stress Markers, TGF- $\beta 1$ and MMP-13. Open Access Maced J Med Sci. 2020: 8(A):555-562.

24. Patanella AK, Zinno M, Quaranta D, Nociti V, Frisullo G, Gainotti G, et al. Correlations Between Peripheral Blood Mononuclear Cell Production of BDNF, TNF-alpha, IL-6, IL-10 and Cognitive Performances in Multiple Sclerosis Patients. Journal of Neuroscience Research. 2010;88:1106-12.

25. Qi Z, He J, Zhang Y, Shao Y, Ding S. Exercise training attenuates oxidative stress and decreases p53 protein content in skeletal muscle of type 2 diabetic Goto-Kakizaki rats. Free Radic Biol Med. 2011;50(7):794-800.

26. Beck AT, Epstein N, Brown G, Steer RA: An inventory for measuring clinical anxiety: psychometric properties. Journal of Consulting and Clinical Psychology. 1988, 56: 893-897.

27. Wycherley TP, Brinkworth GD, Noakes M, Buckley JD, Clifton PM. Effect of caloric restriction with and without exercise training on oxidative stress and endothelial function in obese subjects with type 2 diabetes. Diabetes, Obesity and Metabolism. 2008;10(11):1062-73. 21.

28. Soslu R, Özer Ö, Çuvalcioglu IC. The Effects of Core Training on Basketball Athletes' Antioxidant Capacity. Journal of Education and Training Studies. 2018;6(11):128-34. 22. 
29. Schneider CD, Barp J, Ribeiro JL, Belló-Klein A, Oliveira AR. Oxidative stress after three different intensities of running. Canadian journal of applied physiology. 2005;30(6):723-34.

30. Gupt AM, Kumar M, Sharma RK, Misra R, Gupt A. Effect of moderate aerobic exercise training on autonomic functions and its correlation with the antioxidant status. Indian J Physiol Pharmacol. 2015;59(2):162-9.

31. Songstad NT, Kaspersen KH, Hafstad AD, Basnet P, Ytrehus K, Acharya G. Effects of high intensity interval training on pregnant rats, and the placenta, heart and liver of their fetuses. PloS one. 2015;10(11).

32. Amirkhizi F, Siassi F, Dhahraki SH, Jalali M. Valuation of Oxidative Stress and Total Antioxidant Capacity in Women with General and Abdominal Adiposity. medical journal of mashhad university of medical sciences. 2012;55(3):170-7. (in Persian)

33. Soares JP, Silva AM, Oliveira MM, Peixoto F, Gaivão I, Mota MP. Effects of combined physical exercise training on DNA damage and repair capacity: role of oxidative stress changes. Age. 2015 Jun 1;37(3):61.

34. Aziza SA, Abdel-Aal SA, Mady HA. Chemopreventive effect of curcumin on oxidative stress, antioxidant status, DNA fragmentation and caspase-9 gene expression in 1, 2- dimethylhydrazineinduced colon cancer in rats. American J Biochem Mol Biol. 2014;4:22-34.

35. Háznagy-Radnai E, CzigleS, Zupkól, Falkay G, Máthel. Comparison of antioxidant activity in enzymeindependent system of six Stachys species. Fitot erapia. 2006; 77(7-8): 521-524.

36. Kobra Rahzani, Ali Akbar Malekirad, Akbar Zeraatpishe, Naser Hosseini, Seyed Mohammad Reza Seify, and Mohammad Abdollahi. Anti-Oxidative Stress Activity of Stachys lavandulifoliaAqueous Extract in Human. Cell J. 2013 Winter; 14(4): 314-317.

37. ADA. Diagnosis and classification of diabetes mellitus. Diabetes. 2004;27(1):5- 10.

38. Smits JAJ, Berry AC, Rosenfield D, Powers MB, Behar E, Otto MW. Reducing anxiety sensitivity with exercise. Depression and Anxiety. 2008;25:689-99.

39. Andreas Broocks, Borwin Bandelow, Gunda Pekrun, Annette George, Tim Meyer, Uwe Bartmann, et al. Comparison of Aerobic Exercise, Clomipramine, and Placebo in the Treatment of Panic Disorder. Am J Psychiatry. 1998;155:603-9.

40. Broman-Fulks JJ, Storey KM. Evaluation of a brief aerobic exercise intervention for high anxiety sensitivity. Anxiety Stress Coping 2008;21:117-28.

41. Osali A, Kordi M, Azad A. The Effects of Carbohydrates and Branched Chain Amino Acid Supplements Consumption in Recovery Period on Secretion of Insulin and Preserving the Performance of Wrestlers. journal of sport biosciences. 2009;1(2):129-272.

42. Davis JM, S.P. Bailey, J.A.Woods, F.J. Galiano, M.T. Hamilton, Bartoli WP. Effects of carbohydrate feedings on plasma free tryptophan and branched-chain amino acids during prolonged cycling. . European Journal of applied and Occupational Physiology. 1992;65:513-9.

43. Blomstrand E. Amino acids and central fatigue. Amino Acids J Physiol Endocrinol Metab. 2001;20(1):25-34. 
44. Zorilla EP LL, McKay JR, Roesnthal R, Houldin A, Tax A, et al. . The relationship of depression and stressors to immunological assays: A meta-analytic review. Brain Behav Immun. 2001;15:199-226.

45. Mossner R MO, Koutsilieri E, Saoud M, Ehlis AC, Muller N, et al. Consensus paper of the WFSBP Task Force on Biological Markers: Biological markers in depression. World J Biol Psychiatry. 2007;8:14174. 